\title{
Tentative Analysis of News from the Perspective of Interpersonal Metafunction
}

\author{
Bei Chen* \\ Anshun Vocational and Technical College Guizhou Anshun 561000,China.
}

\begin{abstract}
News reports as a special genre are not reliable and credible as we imagine. They do not only report news facts, but also express some kind of attitudes which will influence readers' judgments. According to interpersonal metafuction, it is possible to dig up the reporters' or speakers' ideology in discourse analysis through modal verbs, modal auxiliaries, modal adjectives, modal lexical words, sometimes through tenses.

Keywords: Interpersonal Metafunction; Basic Speech Roles; Modality; Tense; News
\end{abstract}

\section{Introduction}

Halliday puts forward three metafunctions of language including the ideational, the interpersonal, and the textual metafunction by observing children's acquisition of language. According to the interpersonal metafunction, there are four basic speech roles: giving information; demanding information; giving goods-and-services; and demanding goods-and-services.

In the report we discussed, there are twenty-two sentences in total and all of them are declarative clauses. Declarative is such clause which aims at giving information not exchanging information or demanding services. One of the typical features of News is to show readers the facts that happen around them. The essence of news is to respect facts, to seek truth from the facts, which also is the requirement for news authenticity. From this aspect, declarative mood is the best choice used in news.

\section{The Analysis of Modal Value Verbs}

People can ask information, requests and express intentions or desires through these four functions so that they can achieve their communication purposes through this basic functions. At the same time they also can show our feelings, attitudes, evaluations and judgments, all of which can be realized by the modal verb, the modal auxiliaries, modal adjectives, modal lexical words ,sometimes through tenses.

Value is another variable of modality expressing the intensity of modal elements and can be ranked as high, median or low. The high value of 'obligation' is most often realized through must, ought to, need, ect. These models can be used in specific genre for some certain purposes, such as lay obligation and show confidence or demand actions. Median value modal verbs are mainly represented by will, would , and should. Low value modals, including may, might, can, could, are used to show reasoned and objective argument

Three values of modal verbs in Report

\begin{tabular}{|c|c|c|c|}
\hline & & Frequency & \\
\hline & must & 0 & \\
\hline High & need & 0 & \\
\hline & ought to & Frequency & \\
\hline & & 2 & \\
\hline Median & will & 7 & \\
\hline & would & 0 & \\
\hline & should & Frequency \\
\hline
\end{tabular}

Copyright (C) 2020 Bei Chen

doi: 10.18282/l-e.v9i4.1706

This is an open-access article distributed under the terms of the Creative Commons Attribution Non-Commercial License (http://creativecommons.org/licenses/by-nc/4.0/), which permits unrestricted non-commercial use, distribution, and reproduction in any medium, provided the original work is properly cited. 


\begin{tabular}{|c|c|}
\hline & 0may \\
\hline Low & 0might \\
\hline & 0 can \\
\hline & 2could \\
\hline
\end{tabular}

From the figures above, it is clear to see median value verb would is frequently used in this report. The reason why reporters would like to use median value verbs is that these kind words can express uncertainty in a moderate way. When using these words, they can avoid expressing their attitude too directly or extremely.

(1) WASHINGTON - The White House is considering canceling a fall summit between President Barack Obama and Russian President Vladimir Putin in Moscow, a move that would further aggravate the already tense relationship between the two leaders.

(2) Pulling the plug on the US-Russia talks would deepen the tensions between the two leaders.

(3) And it would likely make it even more difficult for the two countries to find common ground on areas of disagreement that plague the relationship.

From these three statements, these three statements are expressed in the third person tone, which can convey the news facts much more objectively. The reporter seems to try his best to tell the readers there will be something serious happening if the White House cancels the fall summit between Present Obama and Russian President Putin. In sentence1, and 13 , the unpleasant result is that the move will worsen the relationship between the two leaders. In sentence 14, the bad result is that such move will influence different aspects of the two countries. While the reporter choose to employ median value verb would, in this way those serious issues can be much more acceptable. Firstly, high value verbs are usually used for specific purposes such as demanding or certainty ,and such verbs can increase the force of the reporter' argument, while unlike high value verbs would can avoid absoluteness. Such serious results are some hypotheses which come from the reporter or the side he stands for. As for readers, nobody wants to see some bad things happen especially American people and Russians. When readers read this part, they can get an impression that if Russia doesn't considering the issue about Edward Snowden's temporary asylum petition carefully, something serious will occur. To some extent, Russian should take more responsibility for it, while America is innocent. If the reporter express such sensitive topic directly with certain tone, maybe the credibility of the news will be reduced. Secondly, compared with the low value verbs, median value verbs are much more reliable and credible. If lots of low value verbs are used widely, the discourse voice is too weak. Then readers will doubt whether the news is true or not. Especially in such sensitive topic, once the voice of the news is declined, there is no possibility to arouse public attention.

Obviously, from the analysis of would, it is easy to find out the attitude and purposes of the reporter or the side he stands for. The first purpose is simple, just to tell readers what is happening. Secondly, the reporter wants to arouse readers' attention to this issue in a moderate way and trying to convince them. Such descriptions about the seriousness of the problem bring a lot of worries to people. While the usage of would can softened the tone and express the same worries. More importantly, it is a good way to protect the side he stands for and avoid liability. Then let the people understand The White House is forced to cancel the meeting with Putin and The White House is innocent if those serious stuffs happen. Readers can accept the fact unconsciously.

The median value verb would plays a vital role in Report 5 . The median value verbs express speculation. News reports are not as objective as we imagine. Usually they want to convey their attitude in indirect way, while it is abrupt to impose some attitude into readers, so reporters tend to pay attention to the usage of modal verbs which can help them achieve their purpose.

\section{The Analysis of Tenses}

Except modal verbs, tense is another important method to realize modality, Peanington $(1988: 3,4)$ even argue that the English tense system interpret modality in nature, not only a symbol of time. That is to say, if we want to dig out what the writer' meaning is, it is necessary to analyze tenses from interpersonal metafunction not just from syntax and semantics.

Besides, we use the present continuous tense to talk about things that are happening now or these days, but this tense has uncertainty and transiency.

(1) WASHINGTON - The White House is considering canceling a fall summit between President Barack Obama and Russian President Vladimir Putin in Moscow, a move that would further aggravate the already tense relationship between the two leaders.

(2) The White House is dangling that option over the Russians as Moscow considers a temporary asylum petition from Edward Snowden, the American accused of leaking information about classified US intelligence programs.

(3) By simply considering cancellation of the trip, the Obama administration is indicating its concern the Kremlin will allow Snowden to take refuge in Russia.

These three statements have something in common: the subject and the tense. The subject is the authority of US and the tense is present progressive. When talking about Edward Snowden' refuge in Russian, the reporter uses present progressive to describe the attitude of the authority in this news. These three statements report that the authority is considering canceling the summit between President Barack Obama and Russian President Vladimir Putin in Moscow. If this statement is described by past tense, which means the meeting between the two leaders must have been cancelled and there is no possibility to change. In that case, it seems much more abrupt for USA to make these decisions, which are unacceptable for Russia. While the reporter employs present progressive, the usage of present progressive will give readers such a impression that the action has not been done, there 


\title{
Psychological transformation methods and Countermeasures of higher vocational students with mathematics learning disabilities
}

\author{
Daquan Chang* \\ WuXi City College of Vocational Technology, Wuxi 214000, Jiangsu, China.
}

\begin{abstract}
In recent years, the learning disabilities of vocational school students for their weak mathematical foundation and lack of interest have become a hot topic in vocational education. Mathematics learning disabilities of vocational school students are not only objective learning difficulties, but also subjective learning psychology problems. Exploring the psychology transformation methods and countermeasures of mathematics learning disabilities of higher vocational students provides an important reference for solving this problem.
\end{abstract}

Keywords:learning disabilities;psychology; transformation methods

Fund project:2020 WuXi City College of Vocational Technology Scientific Research Project: Research on the Psychological Assistance Mechanism of Higher Vocational Students' Mathematics Tiredness Dilemma(NO.WXCY-2020-KY-20)

In recent years, the number of students in my country's higher vocational colleges has continued to expand, the entrance scores of students are not high, and the students' basic cultural knowledge is generally poor. Most students feel embarrassed by the advanced mathematics, economic mathematics and other courses offered by the school. They are generally struggling to study and have low interest. After a period of study for newly enrolled vocational students, if their mathematics learning difficulties cannot be resolved in time, they will often fall into serious mathematics learning obstacles. This situation will greatly affect students' learning effects on subsequent professional courses based on mathematics, and also hinder the improvement of the quality of talent

Copyright (C) 2020 Daquan Chang

doi: 10.18282/1-e.v9i4.1707

This is an open-access article distributed under the terms of the Creative Commons Attribution Non-Commercial License (http://creativecommons.org/licenses/by-nc/4.0/), which permits unrestricted non-commercial use, distribution, and reproduction in any medium, provided the original work is properly cited.

is possibility to prevent it, but whether it happens or not depends on Russia. If Russia makes a concession that Kremlin will not allow Snowden to take refuge in Russia, the White house will not cancel the summit then there will not be any problems between these two countries. The analysis of present progressive in report can help us understand that the White House hopes that Russian can refuse to help Edward Snowden. On one hand, this news should report facts, but at the same time, the standpoint requires the description to have the function of alerting. On the other hand, present progressive softens the voice of the decision made by the USA, and indirectly tell readers that what they will do is not their true will. If the decision has been made, Russia should take responsibility for it.

\section{Conclusion}

From what has been analyzed above, we can know that the usage of modal verbs and tense can help us dig up the attitudes of the reporter or the side he stands for. Different modal verbs will describe different feelings. Correct usage of them can avoid absoluteness and let readers accept the information easily. Besides, the functions of tense cannot be limited in time, they also can realize the interpersonal function in some certain context.

\section{Bibliography:}

[1]Thompson G.Introducing Functional Grammar[M]. Beijing: Foreign Language Teaching and Research Press ,2000:28

[2]He Wei. modal usage of tenses: grammatical metaphors [J]. foreign language and foreign language teaching ,2008,(7).

[3]He Wei. A Comprehensive Study of Foreign English Temporal Studies [J].]1 Journal of PLA Foreign Language Institute, $\mathrm{a}(1) .2006$

[4]He Wei. A Study on Systemic Functional Grammar of Tense Clauses [J].] Hierarchy Foreign Language and Foreign Language Teaching, b(8).2006

[5]Ginna. A Study on the Evaluation Function of Tenses Foreign Language and Foreign Language Teaching ,2009(8):24-25...

[6]Xie Wei. A Study on the Meaning of English Modal Verbs Journal of Hunan Institute of Humanities and Science and Technology ,2007,(2)

[7]Zhao Pu. A Semantic and Pragmatic Analysis of the Meaning of Modal Auxiliary Verbs in English [J].]1 Foreign Language Studies,2004,(2). 